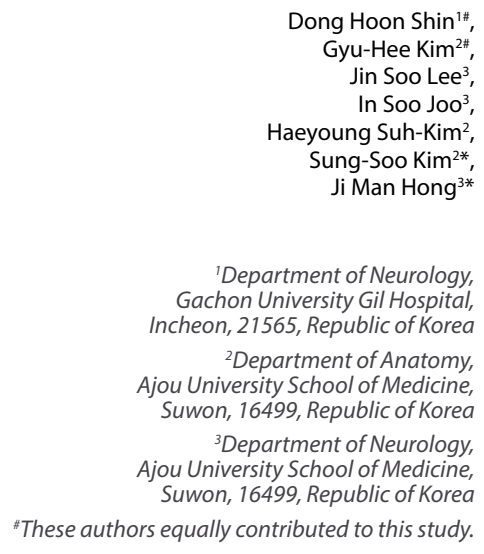

Received 30 July 2016 accepted 29 November 2016

\title{
COMPARISON OF MSC- NEUROGENIN1 ADMINISTRATION MODALITY IN MCAO RAT MODEL
}

\section{Abstract}

Intracerebral (IC) grafting of mesenchymal stem cells (MSCs) is not currently used in humans due to its potential complications. On the other hand, intra-arterial (IA) administration can be facilitated for engrafting of intensified MSCs in the injured human brain. The study is designed to compare the two methods of MSC administration using IA and IC routes through the parameters of behavior, infarct volume, cell distribution, and MSC identification. An ischemic stroke model was generated in Sprague Dawley male rats. This experiment used MSCs/Ngn 1 that express Neurogenin 1 (Ngn1) to ensure grafted MSC maintenance. MSCs/Ngn1 or normal saline was administrated via the IC or IA route on day 3. All animals were randomly assigned into four groups (five rats in each group): IC-control, IA-control, IC-MSCs/Ngn1, or IA-MSCs/Ngn1. Motor behaviors, infarct volume, and distribution of superparamagnetic iron oxide (SPIO)-labeled cells on magnetic resonance imaging (MRI) were compared from each group. There were no baseline differences in motor behaviors or infarct volume between IC-MSCs/Ngn 1 and IA-MSCs/Ngn1. Hovever, the IA-MSCs/Ngn1 group showed the greatest recovery on Rotarod testing and adhesive removal tests ( $p=0.003$ and $p=0.009$ vs. IC-MSCs/Ngn1, respectively). The IA-MSCs/Ngn1 group also had more evenly distributed SPIO-labeled cells on MRI. The results suggest that IA administration is likely to be beneficial for humans based on its ability to improve behavioral outcomes and ensure even MSC engrafting.

Keywords

Brain ischemia • Cell transplantation • Mesenchymal stem cells

downstream transcription factors such as NeuroD [9]. A previous study demonstrated that intracerebral (IC) administration of Ngn1expressing MSCs (MSCs/Ngn1) produced restorative augmentation of behavioral functions and induced the expression of neuron-specific proteins and voltage-gated $\mathrm{Ca}^{2+}$ and $\mathrm{Na}^{+}$channels, suggesting survival of the grafted MSCs [10].

Animal experiments have shown that intracerebral (IC) administration is a reliable route for stem cell transplantation [11-13]. IC cell grafting is avoided in the clinical field due to its hazardous complications, such as seizure, chronic subdural hematoma, cortical vein occlusion, and postprocedural clinical deterioration [14-16]. On the other hand, with intravenous (IV) administration the majority of MSCs are entrapped within the lung and liver before they are targeted to the brain, which potentially reduces their therapeutic potential $[5,17]$.
Theoretically, intra-arterial (IA) cell grafting is more feasible in clinical applications because of more predictable engrafting (vs. IV approach) and less invasiveness (vs. IC approach). An animal study reported that IA administration of bone marrow stromal cells can facilitate axonal sprouting and remyelination in the cortical ischemic boundary zone and improve neurological function [18]. Recent animal studies showed that IA administration is a safe and more effective method than IV administration for treating cerebral ischemia $[19,20]$. Nonetheless, there are no comparative studies on the engrafting effectiveness of IA versus IC stem cell administration. Therefore, the purpose of this study was to investigate behavioral changes, infarct volume, cell distribution, and stem cell identification in IA and IC MSC/Ngn1 groups in a rat model with ischemic stroke. neuronal differentiation as an activator for 


\section{Materials and methods}

\section{MSCs/Ngn1 preparation}

MSCs were isolated from human bone marrow with approval of the Institutional Review Board of Ajou University Medical Center (Suwon, Republic of Korea). Human MSCs were transduced to prepare the MSCs/Ngn1 as previously described [10]. Briefly, MSCs were transduced with Ngn1-expressing retrovirus for 8 hours in the presence of $4 \mu \mathrm{g} / \mathrm{mL}$ polybrene (Sigma-Aldrich, St. Louis, MO, USA) and $10 \mathrm{ng} /$ $\mathrm{mL}$ basic fibroblast growth factor (bFGF, Dong-A Pharmaceutical Co., Youngin, Republic of Korea). The transduced cells were enriched for 2 weeks in the presence of $2 \mu \mathrm{g} / \mathrm{mL}$ puromycin (Sigma-Aldrich, St. Louis, MO, USA) and maintained by subculturing every 5 to 7 days in the growth medium, which was composed of Dulbecco's modified Eagle's medium (Welgene, Daegu, Republic of Korea) supplemented with $10 \%$ fetal bovine serum (HyClone, Logan, UT, USA), 100 units $/ \mathrm{mL}$ penicillin, and $100 \mu \mathrm{g} / \mathrm{mL}$ streptomycin (Gibco, Grand Island, NY, USA).

\section{Middle cerebral artery occlusion (MCAO)}

All animal protocols were approved by the Institutional Animal Care and Use Committee of Ajou University Medical School (Suwon, Republic of Korea). A transient focal ischemia model of 120-minute MCAO with an intraluminal filament was performed in male Sprague Dawley rats (approximately $250 \mathrm{~g}$ ) according to a modified procedure originally described by Longa et al. [21]. Briefly, anesthesia was induced with $5 \%$ isoflurane in $70 \% \mathrm{~N}_{2} \mathrm{O}$ and $30 \% \mathrm{O}_{2}$ and maintained at 3\% isoflurane. A 4-0 monofilament nylon suture with a rounded tip was introduced into the external carotid artery (ECA) lumen and gently advanced into the internal carotid artery (ICA) until it blocked the bifurcating origin of the MCA. The suture was removed two hours after MCAO. A double screen-out method was employed to ensure consistent ischemic injuries between rats. First, test subjects with negligible or moderate ischemic symptoms on any type of behavior tests on day 1 were excluded. Second, rats with a small infarct only involving the striatum or cortex were excluded after magnetic resonance imaging (MRI) analysis on day 2 (Supplementary Fig. 1). Twenty two animals showing a similar degree of neurologic deficit on behavior tests and similar infarct pattern and volume on MRI

$A$

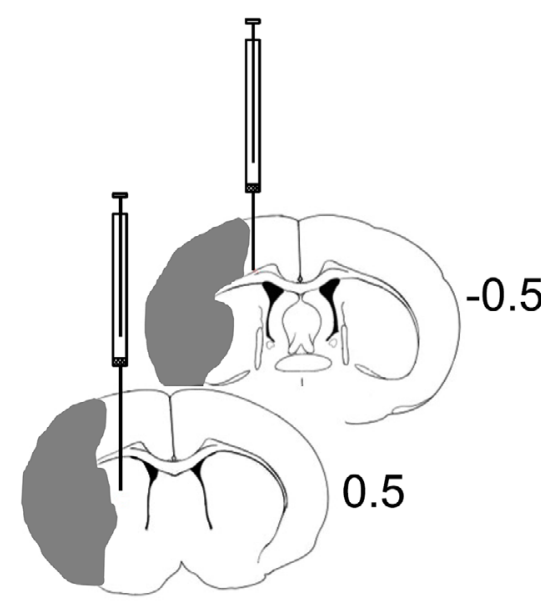

Intra-cerebral were selected and randomly assigned to the following groups: (I) to receive normal saline (NS) via the IA route $(n=5)$, (II) to receive NS via the IC route $(n=5)$, (III) to receive MSCs/Ngn1 via the IA route ( $n=5)$, and (IV) to receive MSCs/ Ngn1 via the IC route $(n=5)$ (Table 1).

\section{Transplantation}

Three days after MCAO the animals were anesthetized with $5 \%$ isoflurane in $70 \% \mathrm{~N}_{2} \mathrm{O}$ and $30 \% \mathrm{O}_{2}$ using an induction chamber and maintained at $3 \%$ isoflurane using a face mask. After the skull was opened, MSCs/Ngn1 (1.0 $x 10^{6}$ cells) or NS in a total fluid volume of 10 $\mu \mathrm{L}$ were $\mathrm{IC}$ transplanted into the striatum (anteroposterior [AP], 0.5; mediolateral [ML],

B

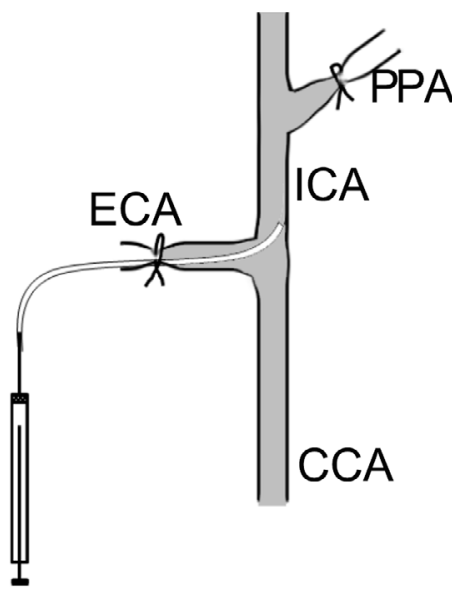

Intra-arterial

Figure 1. Routes of stem cell administration. A. Rat was anesthetized, skull exposed, and cells were intra-cerebrally transplanted into the cortex and striatum in the ipsilateral hemisphere using a stereotactic apparatus. Numbers indicate the distance (in $\mathrm{mm}$ ) anterior to bregma and shading indicates the region of ischemic damage. B. Rat was anesthetized, common carotid artery (CCA) ligated, followed by insertion of a catheter tip to the CCA bifurcation through external carotid artery (ECA), and intra-arterial administration of cells was performed. ICA, internal carotid artery; PPA, pteryopalatine artery.

Table 1. Experimental animal groups.

\begin{tabular}{|c|c|c|c|c|c|}
\hline Group & Cell labeling & Transplantationt & Assay & End point & Figures \\
\hline I & \multirow[t]{4}{*}{-} & IC, NS $(n=5)$ & $M R I^{*}$ & \multirow[t]{4}{*}{$28 d$} & \multirow[t]{4}{*}{ Fig. $2 \& 4$} \\
\hline ॥ & & IA, NS $(n=5)$ & $\begin{array}{c}\text { Behavior test* } \\
\text { Cresyl violet stain }\end{array}$ & & \\
\hline III & & IC, MSCs/Ngn1 $(n=5)$ & Immunohistochemistry & & \\
\hline IV & & IA, MSCs/Ngn1 $(n=5)$ & & & \\
\hline V & \multirow[t]{2}{*}{ SPIO } & IC, MSCs/Ngn1 $(n=1)$ & MRI cell tracking & \multirow[t]{2}{*}{$7 d$} & \multirow[t]{2}{*}{ Fig. 3} \\
\hline $\mathrm{Vl}$ & & IA, MSCs/Ngn1 $(n=1)$ & $\begin{array}{l}\text { Prussian blue stain } \\
\text { Immunohistochemistry }\end{array}$ & & \\
\hline
\end{tabular}

*Middle cerebral artery occlusion (MCAO) was validated by behavior test on day 1 and magnetic resonance imaging (MRI) on day 2 .

†Transplantation was carried out on day 3

Abbreviations: IC = intra-cerebral, IA = intra-arterial, NS = normal saline, MSCs/Ngn1=Ngn1-expressing mesenchymal stem cell 
2.5; dorsoventral [DV], 5.0) and cortex (AP, -0.5; $M L, 2.0 ; D V, 2.5)$ in the ipsilateral hemisphere using a stereotactic apparatus (David Kopf Instruments, Tujunga, CA) (Fig. 1A). IA administration was performed as previously described [22] with modifications. Briefly, the CCA was ligated, and a catheter (25G) tip was inserted to the common carotid artery (CCA) bifurcation through the ECA. After blood flow from the CCA to ICA was recovered by CCA occlusion release, stem cells $\left(1 \times 10^{6}\right)$ in 1.2 $\mathrm{mL}$ saline were directly injected into the CCA bifurcation over the course of 5 minutes (Fig. 1B).

\section{Behavioral testing}

Tests were performed to measure motor and sensory behaviors. The battery consisted of the Rotarod test and adhesive removal test. All animals were trained for 7 days before MCAO induction. Only the animals capable of remaining on the Rotarod cylinder for more than $300 \mathrm{~s}$ and removing adhesive dots within 10 seconds were used for the experiment. In the Rotarod test, the Rotarod cylinder (Ugobasile, Comerio, Italy) was accelerated from 4 to 40 rpm within 5 minutes, and the amount of time each animal remained on the Rotarod was measured with a cut-off time of 300 seconds. The data are presented as the percentage of the mean duration from three trials before MCAO. For adhesive removal tests, square dots of adhesive-backed paper $\left(100 \mathrm{~mm}^{2}\right)$ were used as bilateral tactile stimuli occupying the distalradial region on the wrist of each forelimb. The time taken for each animal to remove each dot was recorded, and the animals were given 3 trials with a cut-off time of 300 seconds. The data are presented as the mean time to remove the dots. We performed behavior tests at 1, 7, 14 , and 28 days after MCAO.

\section{Infarct volume measurement}

MRI scanning was performed using a $3.0 \mathrm{~T}$ whole-body MRI scanner (Achieva 3.0T X-Series Qasar Dual, Philips Healthcare, Amsterdam, Netherlands) equipped with a gradient system capable of 35 milliteslas/m at 3, 7, 14, and 28 days after MCAO. A fast-spin echo imaging sequence was used to acquire T2-weighted anatomical images of the rats' brains in vivo, using the following parameters: repetition time, 4,000 milliseconds; effective echo time, 96 milliseconds; field of view, 55 x $55 \mathrm{~mm} 2$ image matrix, $256 \times 256$; slice thickness, 1.5 $\mathrm{mm}$; flip angle, $90^{\circ}$; number of excitations, 2; and pixel size, $0.21 \times 0.21 \mathrm{~mm} 2$. A 300-mm diameter quadrature 16-ring birdcage coil arrangement was used for RF excitation, and a 40-mm diameter saddle coil was used for signal detection. A total of 15 slices were scanned to cover the entire brain. For each slice, the ischemic area from each T2-weighted image was manually marked and calculated using the software program Osiris (University of Geneva, Geneva, Switzerland).

Relative infarct volume (RIV) was normalized as described by Neumann-Haefelin et al. [23] using the equation RIV $=(\mathrm{LT}-(\mathrm{RT}-\mathrm{RI})) \mathrm{x} \mathrm{d}$, in which LT and RT represented the areas of the left and right hemisphere, respectively, in square millimeters; RI was the infarcted area in square millimeters; and $d$ was the slice thickness (1.5 $\mathrm{mm}$ ). RIV was expressed as a percentage of the right hemispheric volume.

\section{In vivo tracking of superparamagnetic} iron oxide (SPIO)-labeled cells

MSCs/Ngn1 were labeled using ferridex (Ferridex IV, TAEJOON Pharm, Republic of Korea) and protamine sulfate (Sigma-Aldrich, St. Louis, MO, USA) according to the procedure described by Arbab et al. [24]. A Prussian blue staining method [24] was used to identify ferridex incorporation in the MSCs/Ngn1. We transplanted the SPIO-labeled MSCs/Ngn1 via IC and IA administration as described above. Distribution and migration of MSCs/ Ngn1 were serially monitored by MRI using the SPIO-labeled MSCs/Ngn 1 after $4 \mathrm{~h}$ and 1, 4, and 7 days. To identify labeled MSCs/Ngn1 in ischemic brains, animals were sacrificed 7 days after transplantation. Transplanted cells were detected by Prussian blue staining and immunohistochemistry using anti-human mitochondria (hMT, 1:100, Millipore, Temecula, CA, USA) or anti-CD68 (ED1, 1:200, Abcam, Cambridge, MA, USA) antibodies.

\section{Histological analysis}

Twenty-eight days after transplantation, the anesthetized rats were transcardially perfused with $0.9 \%$ saline followed by $4 \%$ paraformaldehyde (PFA). Their brains were removed, postfixed in 4\% PFA overnight, and then cut through the areas of interest after embedding in paraffin. Serial $6-\mu m$-thick paraffin sections were deparaffinized and then placed in boiled citrate buffer $(\mathrm{pH}$ 6.0) for 10 minutes. After blocking in $1 \%$ bovine serum albumin (BSA) and 5\% normal serum, the sections were incubated with antibodies against MAP2 (microtubule-associated protein 2, 1:100, Sigma-Aldrich, St. Louis, MO, USA), which is a marker for the mature neuron; ED1 (1:200, Abcam, Cambridge, MA, USA) to detect phagocytic activity; and hMT (1:100, Millipore, Temecula, (A, USA), which is a marker for transplanted human stem cells, at $4^{\circ} \mathrm{C}$ overnight. Then, the sections were incubated with Alexa Fluor 488- or 594-conjugated antiIgG secondary antibodies and counterstained with bis-benzamide (Molecular Probes, Eugene OR, USA) to visualize the entire population of cells. Fluorescent images were acquired using a Zeiss LSM510 confocal microscope (Carl Zeiss, Oberkochen, Germany).

\section{Statistical analysis}

Comparisons between the two groups were achieved using Student's unpaired $t$-test. Multiple comparisons for each treatment group were analyzed using one-way analysis of variance (ANOVA) with the independent variables being treatment groups and days of testing. These were followed by Tukey's post hoc tests. All statistical analyses were performed using SPSS version 12.0 (SPSS Inc., Chicago, IL, USA), and the results were used for multiple comparisons.

\section{Results}

\section{Therapeutic effects of MSCs/Ngn1} according to administration modality The effectiveness of MSCs/Ngn 1 administration in a rat stroke model was evaluated, followed by a comparison of the efficacy between IA and IC administration. Control animals that received IA or IC normal saline spontaneously recovered to a limited degree in the first seven days and then no further improvement was observed during the 28 day study. 
The IC MSCs/Ngn1-transplanted animals showed significantly better performance in Rotarod testing than the IC control group on day 28 (Tukey's post hoc test, $\mathrm{p}<$ 0.0001 on day 28 only). The IA MSCs/Ngn1transplanted animals showed significantly better Rotarod performance than the IA control group from days seven to 28 (Tukey's post hoc test, all $\mathrm{p}<0.05)$. The adhesive removal test revealed greater improvement for the IA MSCs/Ngn1 group compared to the IA control group (Tukey's post hoc test, $\mathrm{p}$ $<0.05$ for days 21 and 28). Interestingly, the IC MSCs/Ngn1 group showed a decrease in functional score on the Rotarod test on day seven compared to other groups (including control groups; this was the periprocedural period after IC stereotactic administration). Functional recovery was higher in the IA MSCs/Ngn1 group than in the IC MSCs/ Ngn1 group for both the Rotarod and adhesive removal tests. On day 28 , the IA MSCs/Ngn1 administration group achieved significantly higher functional scores in the Rotarod test (unpaired t-test, $\mathrm{p}=0.003$ ) and adhesive removal test (unpaired t-test, $\mathrm{p}=0.009)$, compared to the IC MSCs/Ngn1 transplantation group (Fig. 2A, 2B).
Serial changes in infarct volume according to administration modality The RIV of the rat brains were monitored using MRI analysis over the 28-day experimental period (Fig. 2C) and histologic assessments of ischemic rat brains were performed on day 28 (Fig. 2D). No differences were seen in the initial infarct volume ratios between the four groups $(p=0.966)$. Although the ICMSCs/Ngn1 administration group showed a tendency toward a reduced infarct volume ratio compared to the IA control $(p=0.061)$ and IC control $(p=0.223)$, the IA MSCs/Ngn1 administration group showed a significant
A

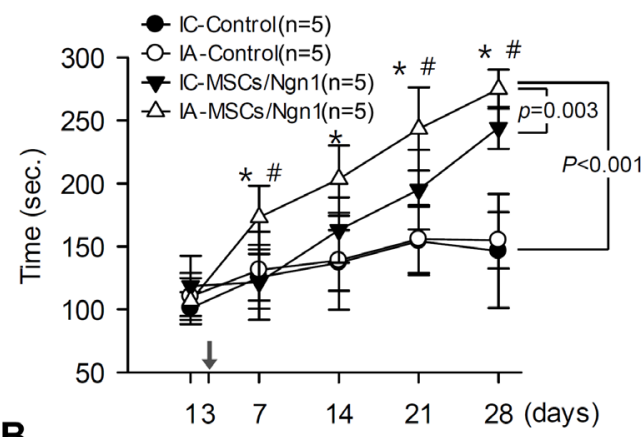

B

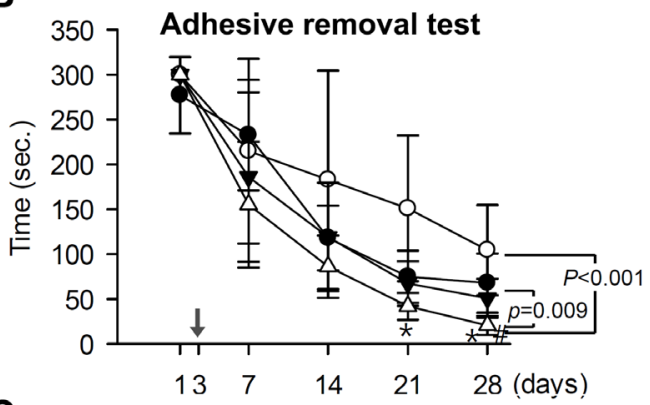

C

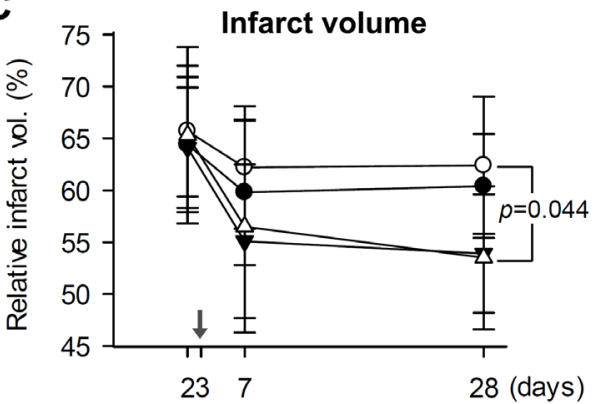

D

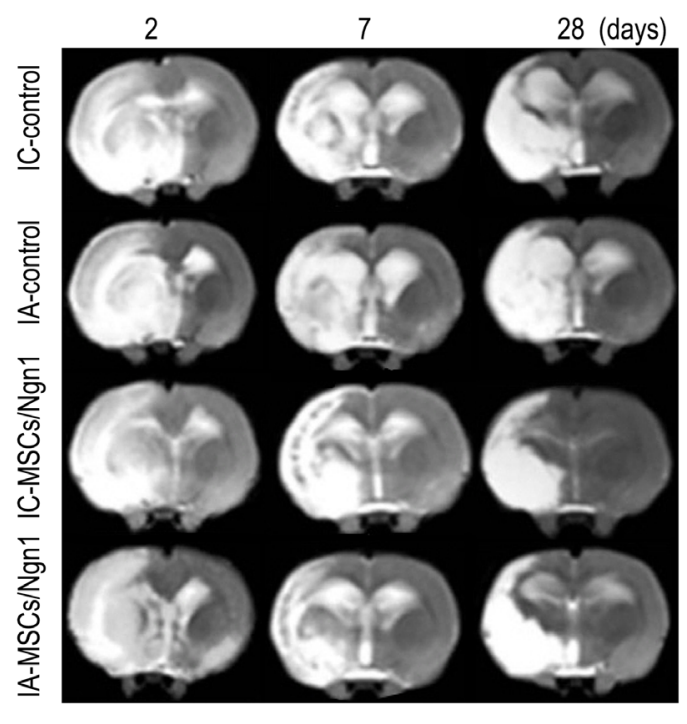

E
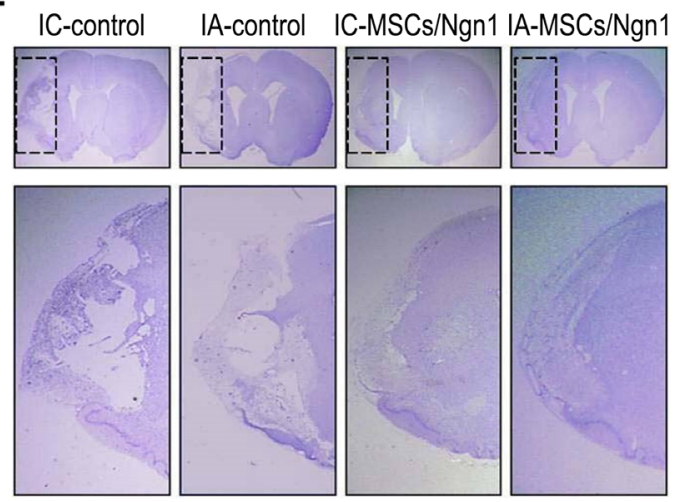

Figure 2. Comparison of functional behavior and serial infarct volume in MRI during 28 days. Behavioral improvements of the animals transplanted with normal saline or MSCs/Ngn1 stem cells via intra-cerebral or intra-arterial route were evaluated by the A. Rotarod test or B. adhesive removal test. MSC/Ngn1 stem cells showed a therapeutic effect compared with the control and the intra-arterial route had better functional recovery compared with the intra-cerebral route. C. Quantitative analysis of infarct volume was evaluated using brain magnetic resonance imaging. Statistical significant differences between the groups were determined by analysis of variance ( ${ }^{*} \mathrm{p}<0.05$ compared with IA-control group; $\# \mathrm{p}<0.05$ compared with IC-MSCs/Ngn1 group). Arrows indicate transplantation time of cells. D. Representative MR imaging from 2 to 28 days after ischemia. E. Cresyl violet staining on day 28 after ischemia. The MSCs/Ngn1 transplanted groups showed more reduced infarct volume on MRI images and histology slides. 
reduction in infarct volume compared with IA controls $(p=0.044)$ and a trend toward that reduction compared with IC controls $(p=0.174)$ (Table 2) at 28 days.

\section{MSCs/Ngn1 distribution according to administration modality}

SPIO labeling was evaluated in MSCs/Ngn1 stained with Prussian blue after ferridex and protamine sulfate incubation for 12 hours (Fig. 3A). The distribution patterns of transplanted MSCs/Ngn1 were discretely different. IA-transplanted SPIO-labeled MSCS/ Ngn1 were widely distributed in the ischemic area, whereas IC-transplanted SPIO-labeled MSCs/Ngn1 on MRI were localized to the stereotactically injected site after four hours. Serial MRI imaging studies on days 1, 4, and 7 showed that each distribution pattern was not dramatically changed from the initial pattern on MRI (Fig. 3B). To identify the SPIO signal on MRI, animals were sacrificed on day 7. The IA MSCs/Ngn1-transplanted ischemic rat brain specimens were stained with Prussian blue to identify SPIO-labeled cells. Identification of MSCs/Ngn1 and phagocytic immune cells was performed with immunohistochemistry using an hMT antibody and ED1 antibody, respectively (Fig. 3 C). Some SPIO remained within the injected MSCs/Ngn1, and other
A

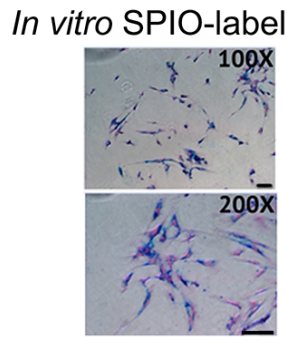

C
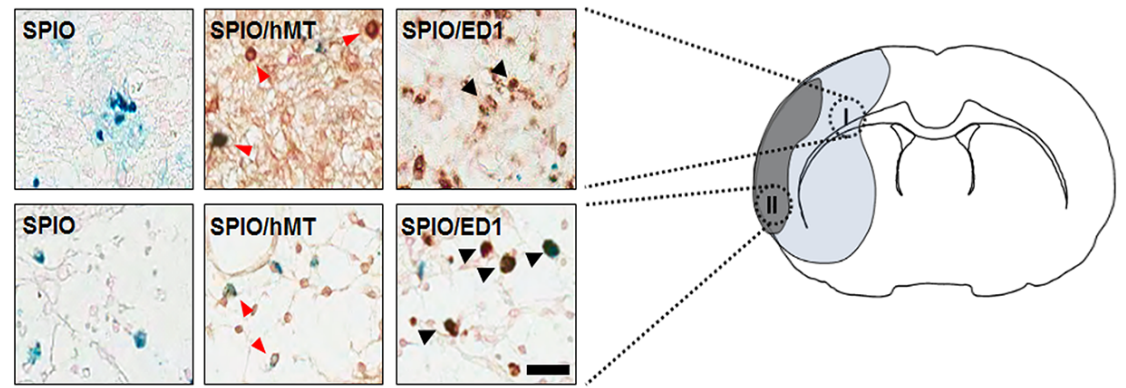

Figure 3. MSCs/Ngn1 tracing by using SPIO labeling. A. MSCs/Ngn1 labeled with ferridex and protamine sulfate. Prussian blue staining for the identification of incorporation of ferridex into the MSCs/Ngn1. B. Distribution of MSCs/Ngn1 was monitored by SPIO labeling on MRI. Intra-arterial transplanted SPIO labeled MSCs/Ngn1 was widely distributed in the ischemic area. Each distribution pattern persisted during the serial MRI imaging studies on days 1,4 , and 7 . C. Prussian blue staining 7 days after the ischemic brain transplantation with intra-arteria MSCs/Ngn 1 cells. Immunostaining to identify transplanted SPIO labeled MSCs/Ngn 1 cells and phagocytic activity (microglia/macrophages), by using anti hMT (human Mitochondria) and ED1 antibodies respectively, was performed in the ischemic boundary (I) and core (II) regions. SPIO correlated with hMT (red arrowheads) and ED1 (black arrowheads). Scale bars $=20 \mathrm{~mm}$.

Table 2. Behavioral tests results and MRI analysis.

\begin{tabular}{|c|c|c|c|c|c|c|c|}
\hline \multirow[t]{2}{*}{ Group } & \multirow[t]{2}{*}{ IC-NS $(n=5)$} & \multirow{2}{*}{$\begin{array}{l}\text { IA-NS } \\
(n=5)\end{array}$} & \multirow{2}{*}{$\begin{array}{l}\text { IC-MSCs/Ngn } 1 \\
(n=5)\end{array}$} & \multirow{2}{*}{$\begin{array}{c}\text { IA-MSCs/Ngn } 1 \\
(n=5)\end{array}$} & \multicolumn{3}{|c|}{$P$ value } \\
\hline & & & & & $\begin{array}{l}\text { IA-MSCs/Ngn } 1 \text { vs. } \\
\text { IC-NS }\end{array}$ & $\begin{array}{l}\text { IA-MSCs/Ngn1 vs. } \\
\text { IA-NS }\end{array}$ & $\begin{array}{l}\text { IA-MSCs/Ngn1 vs. } \\
\text { IC-MSCs/Ngn } 1\end{array}$ \\
\hline \multicolumn{8}{|l|}{ Rotarod test (s) } \\
\hline Day 1 & $101.0 \pm 12.9$ & $110.3 \pm 18.6$ & $118.7 \pm 23.9$ & $106.7 \pm 18.2$ & & & \\
\hline Day 7 & $125.6 \pm 18.5$ & $131.3 \pm 30.6$ & $121.6 \pm 29.8$ & $173.1 \pm 25.3$ & & & \\
\hline Day 14 & $137.2 \pm 37.4$ & $138.9 \pm 24.0$ & $163.1 \pm 25.8$ & $203.6 \pm 26.7$ & $<0.001^{*}$ & $<0.001^{*}$ & $0.003^{\#}$ \\
\hline Day 21 & $154.4 \pm 37.2$ & $155.9 \pm 26.9$ & $195.1 \pm 31.6$ & $243.4 \pm 33.0$ & & & \\
\hline Day 28 & $146.4 \pm 45.2$ & $155.0 \pm 22.4$ & $244.3 \pm 16.7$ & $275.0 \pm 15.5$ & & & \\
\hline \multicolumn{8}{|c|}{ Adhesive removal test (s) } \\
\hline Day 1 & $277.2 \pm 42.6$ & $300.0 \pm 0.0$ & $300.0 \pm 0$ & $300.0 \pm 0$ & & & \\
\hline Day 7 & $232.8 \pm 61.6$ & $214.9 \pm 102.9$ & $186.1 \pm 94.4$ & $155.3 \pm 70.1$ & & & \\
\hline Day 14 & $118.0 \pm 36.0$ & $183.0 \pm 121.7$ & $119.3 \pm 60.3$ & $86.3 \pm 34.8$ & 0.088 & $<0.001^{*}$ & $0.009^{\#}$ \\
\hline Day 21 & $75.0 \pm 29.2$ & $151.1 \pm 81.3$ & $67.4 \pm 24.9$ & $42.0 \pm 15.1$ & & & \\
\hline Day 28 & $68.0 \pm 33.0$ & $104.6 \pm 50.3$ & $51.0 \pm 21.5$ & $20.7 \pm 10.6$ & & & \\
\hline \multicolumn{8}{|c|}{ MRI infarct volume (\%) } \\
\hline Day 2 & $64.4 \pm 6.5$ & $65.7 \pm 6.3$ & $64.1 \pm 5.8$ & $65.3 \pm 8.5$ & & & \\
\hline Day 7 & $59.8 \pm 7.0$ & $62.2 \pm 5.9$ & $55.1 \pm 7.4$ & $56.5 \pm 10.2$ & 0.174 & $0.044^{*}$ & 0.999 \\
\hline Day 28 & $60.4 \pm 5.0$ & $62.4 \pm 6.6$ & $53.9 \pm 5.7$ & $53.5 \pm 6.9$ & & & \\
\hline
\end{tabular}

All data were presented as mean \pm SD.* $\mathrm{p}<0.05$, ANOVA; $\# \mathrm{p}<0.05$, Student's unpaired t-test. Abbreviations: ANOVA, analysis of variance; IA, intra-arterial; IC, intra-cerebral; MRI, magnetic resonance imaging; MSCs/Ngn1, Ngn1-expressing mesenchymal stem cell; NS, normal saline; SD = standard deviation. 
SPIO stained the immune cells, suggesting that immune cells had phagocytosed some MSCs/ Ngn1.

\section{MSCs/Ngn1 transdifferentiation in a} rat stroke model

To assess transdifferentiation of the IAtransplanted MSCs/Ngn1, we identified hMT immunoreactive cells in the ischemic core and border zone on day 28. Most hMT positive cells expressed MAP2 (a neuronal marker) but did not express GFAP (an astrocyte marker).

\section{Discussion}

The experiment demonstrated that MSCs/ Ngn1 have therapeutic properties in an acute ischemic stroke model and provide more benefits when they are administered intraarterially. SPIO-labeled MSCs/Ngn1 delivered via the IA route were more evenly distributed within the infarcted area on MRI, whereas they remained at the injection site in the IC group. Moreover, neuronal differentiation of the IAtransplanted MSCs/Ngn1 in the ischemic area was observed.

Stem cell therapy has emerged as a promising strategy for treating neurological diseases $[25,26]$. MSCs are of particular clinical interest because they are easily isolated from bone marrow, adipose tissue, and umbilical cord blood and can be expanded through as many as 50 population doublings in about 10 weeks [27]. In previous studies, MSCs were shown to ameliorate neurologic dysfunction in patients with acute ischemic stroke $[5,17$,

A
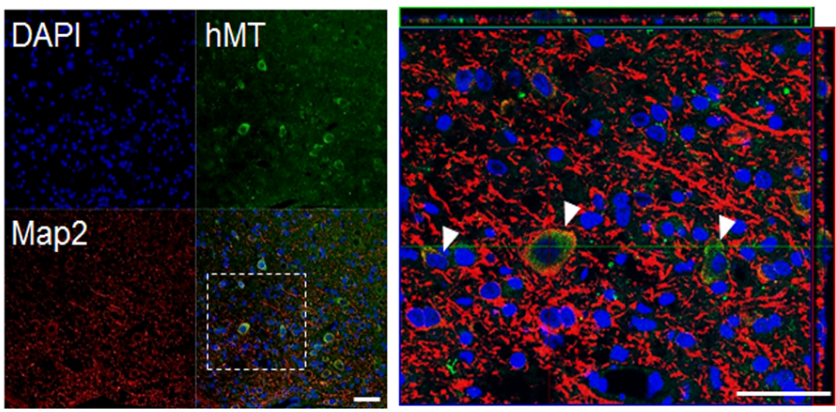

B
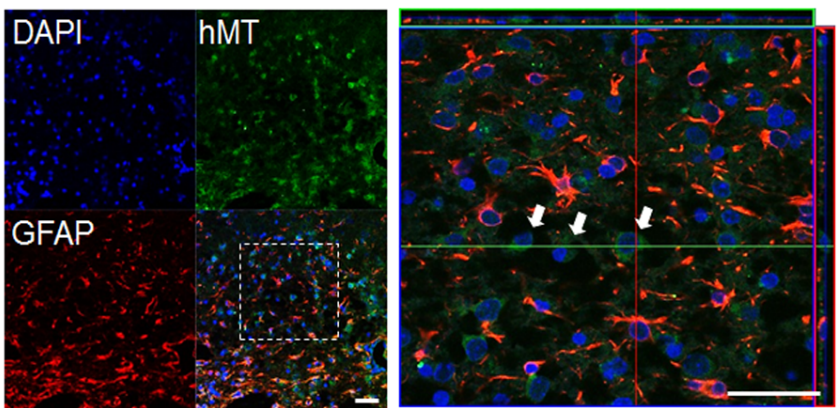

Figure 4. Transdifferentiation of MSCs/Ngn1 4 weeks after intra-arterial grafting. Confocal images of the transplanted cells 4 weeks after ischemia. A. Neuronal transdifferentiated MSCs/Ngn 1 cells were identified by the antiMAP2 (microtubule-associated protein) antibody (neuronal marker) and hMT (human mitochondrial) antibody. Arrowheads denote the donor-derived cells co-localized with cell type specific antigens in enlarged orthographic images. B. None of the MSCs/Ngn1 that identified with anti-hMT antibody (arrows) co-stained with antibody recognizing glial fibrillary acidic protein (GFAP). Scale bars $=20 \mathrm{~mm}$.

\section{T2, $2 \mathrm{~mm}$ thickness}
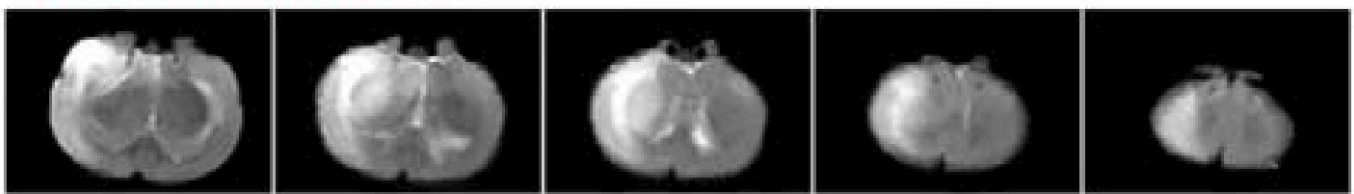

\section{DWI, $2 \mathrm{~mm}$ thickness}
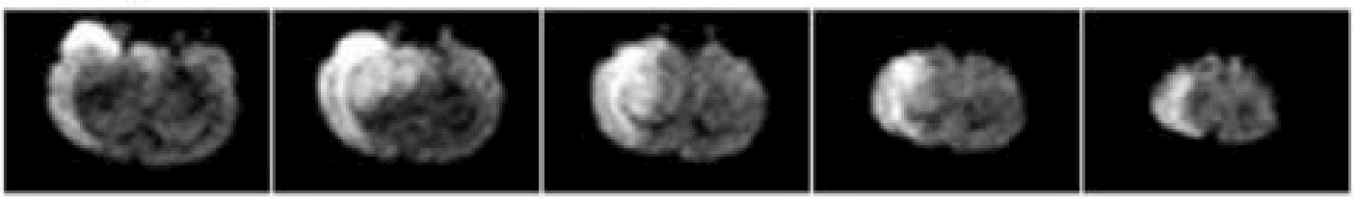

Figure 5. Cerebral infarct in rat model. Infarction of rat brain resulted from the occlusion of middle cerebral artery (MCAo) is documented by T2 and diffusion weight image (DWI) of brain magnetic resonance image (MRI). 
explanation for this is that the paracrine effects of MSCs/Ngn 1 on surrounding tissues, compared to parenteral MSCs, can induce the neurogenesis of resident stem cells in the subventricular zone (SVZ), reduce delayed neuronal cell death in penumbra regions, ameliorate inflammation by activating resident microglia and stimulating infiltration of leukocytes into the microvessels and reduce ischemic cerebral penumbra followed by ischemic insult. Another plausible reason is prolonged survival of MSCs/Ngn1 in the ischemic brain area and a much higher proportion of transdifferentiation into functional neuronal cells in ischemic regions. Therefore, a comparison between IA and IC routes were done using MSCs/Ngn 1 .

The behavior tests showed significantly better functional recovery in the |A-MSCs/ Ngn 1 group compared to the IC-MSCs/Ngn 1 group. This finding indicates that the route of administration of stem cells, which have a beneficial effect for neuronal recovery, can be another important factor in stem cell therapy for stroke treatment. Injected MSCs/ Ngn1 stem cells were evenly distributed in the IA-MSCS/Ngn1 group on serial MRIs using SPIO-labeled MSCs/Ngn1. However, almost all MSCs/Ngn1 remained around the injected area in the IC-MSCs/Ngn1 group. Theoretically, the paracrine effects of ICengrafted MSCs would be limited because their locations are bound to the vicinity of the injected area. On the other hand, evenly distributed MSCs/Ngn1 administered via IA might facilitate greater paracrine and neuronal transdifferentiation effects by stimulating and revitalizing areas adjacent to ischemic tissue. This result demonstrates that the restorative effect of stem cells is conveyed differently in the ischemic lesion by a different distribution pattern according to administration route and even the distribution is more beneficial for recovery of the neurologic deficit in ischemic stroke.

The experiment confirmed the neuronal differentiation of administered MSCs/Ngn1 cells via IA. The previous report indicated that greater than $45 \%$ of IC-transplanted MSCs/ Ngn1 differentiate into morphologically mature neurons and express functional neuronal proteins such as vesicular glutamate transporter 2 (VGLUT2), NF200, and Tau [10]. However, whether the injected stem cells via IA can be moved into the ischemic lesion and can be differentiated into neuronal cells or not is questionable. This neuronal differentiation of mesenchymal stem cells showed the capability of neuronal induction by genetic engineering through transfection of the $\mathrm{Ngn} 1$ gene. In addition to the restorative paracrine effect, neuronal replacement by differentiation into neuronal cell with mature function may be another mechanism to recover the injured neuronal function by stem cell therapy with MSCs/Ngn1.

Although the IA-MSCs/Ngn1 group showed a significant reduction in infarct volume on MRI compared with IA controls, IA administration of $\mathrm{MSCs} / \mathrm{Ngn} 1$ did not significantly reduce RIV on MRI compared to the IC-MSCs/Ngn1 group in this study. Since we performed behavior tests on day 1 and the brain MRI study on day two serially to verify and include MCAO rat models with similar neurologic impairment and similar infarct volume into our study, we could not avoid the delay of stem cell administration and MSCs/Ngn1 that were administrated on day three from stroke onset in this study. This late treatment with MSCs/Ngn1 may have affected the results, for example leading to low differences in the size of ischemic lesion volume between IA and IC groups.

It is known that IA delivery of MSCs enables efficient cell administration to an infarcted area and it results in significant functional recovery after ischemic stroke in a rat model $[29,30]$. However, the major issue of IA administration is microembolization due to aggregation of the cells in the blood vessels [31]. The major determinants of the safety of IA stem cell administration are cell size, velocity of injection, and cell dose [22, 32]. Janowski et al. [22] showed that administration of MSCs with an infusion velocity over $1 \mathrm{~mL} /$ minute often resulted in stroke whereas a lower velocity $(0.2 \mathrm{~mL} /$ minute) was safe. They also showed that stroke lesions occurred frequently when injecting $2 \times 10^{6} \mathrm{MSC}$, but not after lowering the dose to $1 \times 10^{6}$ cells In this study, we administered a low dose of
MSCs/Ngn1 ( $1 \times 10^{6}$ cells $\left./ 1.2 \mathrm{~mL}\right)$ with a lower infusion velocity $(0.24 \mathrm{~mL} / \mathrm{min})$ to avoid microembolism. We did not find any newly developed microembolic infarcts on MRI scans after MSCs/Ngn1 administration via the IA route, but further assessment of the optimum cell administration procedure is required to evaluate the adverse effects. To minimize the risk of distant embolism in human patients undergoing an endovascular approach, a skilled interventionist and a well-equipped clinical setting are essential for ensuring the safety of IA administration of MSCs or intensified MSCs. Safe IC administration in human patients is technique sensitive and requires general anesthesia. Moreover, the direct deposit of grafting cells via the IC route may inevitably result in damage to the brain parenchyma. For these reasons, previous human trials with the IC route reported both serious and non-serious adverse effects [14-16]. Although IV injection is a clinically relevant and minimally invasive technique, only a small amount of injected cells reach the targeted brain area due to the first pass effect in the lungs and liver [19]. Since the IA route increases the chances of MSC migration and distribution, it facilitates efficient engrafting of stem cells to the target brain areas [33].

The present study compared the therapeutic effect after IC and IA administrations of stem cells. We also showed the hemispheric distributions of injected stem cells on serial MRIs and observed neuronal differentiation on immunohistochemical analyses. The results require cautious interpretation because of the lack of comparisons with surrogate biomarkers for paracrine effects of injected MSCs.

Although we did not find newly formed microembolic strokes on MRI scans after IA delivery of stem cells, we cannot exclude the possibility of microembolsim. It is possible that the microembolisms caused by MSC infusion might be masked by the large ischemic lesions on the MRI. Therefore, continuous stirring should be implemented to prevent distant embolism due to the tendency of MSCs to aggregate. Further human stem cell trials are required to investigate the potential clinical benefits of the IA approach in acute ischemic stroke patients. 


\section{Conclusions}

This study in an acute ischemic stroke model suggests that MSCs/Ngn1 stem cells have promising therapeutic effectiveness. IA administration would be a feasible grafting modality compared to IC administration, based on the behavior test results and MRI analysis.

\section{Acknowledgments}

Conflict of interest statement: The authors do not have any actual or potential conflicts of interest, including financial, personal or academic. This study was supported by a grant from the Bio \& Medical Technology Development Program of the Korean National Research Foundation (NRF2012M3A9C6049725 to S.-S.K).

\section{References}

[1] Pittenger M.F., Mackay A.M., Beck S.C., Jaiswal R.K., Douglas R., Mosca J.D., et al., Multilineage potential of adult human mesenchymal stem cells, Science, 1999, 284, 143-147

[2] Woodbury D., Schwarz E.J., Prockop D.J., Black I.B., Adult rat and human bone marrow stromal cells differentiate into neurons, J. Neurosci Res., 2000, 61, 364-370

[3] Deng W., Obrocka M., Fischer I., Prockop D.J., In vitro differentiation of human marrow stromal cells into early progenitors of neural cells by conditions that increase intracellular cyclic AMP, Biochem. Biophys. Res. Commun., 2001, 282, 148-152

[4] Phinney D.G., Prockop D.J., Concise review: mesenchymal stem/ multipotent stromal cells: the state of transdifferentiation and modes of tissue repair - current views, Stem Cells, 2007, 25, 2896-2902

[5] Bang O.Y., Lee J.S., Lee P.H., Lee G., Autologous mesenchymal stem cell transplantation in stroke patients, Ann. Neurol., 2005, 57, 874-882

[6] Chen J., Li Y., Wang L., Zhang Z., Lu D., Lu M., et al., Therapeutic benefit of intravenous administration of bone marrow stromal cells after cerebral ischemia in rats, Stroke, 2001, 32, 1005-1011

[7] Pittenger M.F., Martin B.J., Mesenchymal stem cells and their potential as cardiac therapeutics, Circ. Res., 2004, 95, 9-20

[8] Ma Q., Kintner C., Anderson D.J., Identification of neurogenin, a vertebrate neuronal determination gene, Cell, 1996, 87, 43-52

[9] Sun Y., Nadal-Vicens M., Misono S., Lin M.Z., Zubiaga A., Hua X., et al., Neurogenin promotes neurogenesis and inhibits glial differentiation by independent mechanisms, Cell, 2001, 104, 365-376

[10] Kim S.S., Yoo S.W., Park T.S., Ahn S.C., Jeong H.S., Kim J.W., et al., Neural induction with neurogenin 1 increases the therapeutic effects of mesenchymal stem cells in the ischemic brain, Stem Cells, 2008, 26, 2217-2228

[11] Yoo S.W., Kim S.S., Lee S.Y., Lee H.S., Kim H.S., Lee Y.D., et al., Mesenchymal stem cells promote proliferation of endogenous neural stem cells and survival of newborn cells in a rat stroke model, Exp. Mol. Med., 2008, 40, 387-397

[12] Irons H., Lind J.G., Wakade C.G., Yu G., Hadman M., Carroll J., et al., Intracerebral xenotransplantation of GFP mouse bone marrow stromal cells in intact and stroke rat brain: graft survival and immunologic response, Cell Transplant., 2004, 13, 283-294

[13] Chen J., Li Y., Wang L., Lu M., Zhang X., Chopp M., Therapeutic benefit of intracerebral transplantation of bone marrow stromal cells after cerebral ischemia in rats, J. Neurol. Sci., 2001,189, 49-57
[14] Kondziolka D., Wechsler L., Goldstein S., Meltzer C., Thulborn K.R., Gebel J., et al., Transplantation of cultured human neuronal cells for patients with stroke, Neurology, 2000, 55, 565-569

[15] Kondziolka D., Steinberg G.K., Wechsler L., Meltzer C.C., Elder E., Gebel J., et al., Neurotransplantation for patients with subcortical motor stroke: a phase 2 randomized trial, J. Neurosurg., 2005, 103, 38-45

[16] Savitz S.I., Dinsmore J., Wu J., Henderson G.V., Stieg P., Caplan L.R., Neurotransplantation of fetal porcine cells in patients with basal ganglia infarcts: a preliminary safety and feasibility study, Cerebrovasc. Dis., 2005, 20, 101-107

[17] Lee J.S., Hong J.M., Moon G.J., Lee P.H., Ahn Y.H., Bang O.Y., A longterm follow-up study of intravenous autologous mesenchymal stem cell transplantation in patients with ischemic stroke, Stem Cells, 2010, 28,1099-1106

[18] Shen L., Li Y., Chen J., Zhang J., Vanguri P., Borneman J., et al., Intracarotid transplantation of bone marrow stromal cells increases axon-myelin remodeling after stroke, Neuroscience, 2006, 137, 393399

[19] Li L., Jiang Q., Ding G., Zhang L., Zhang Z.G., Li Q., et al., Effects of administration route on migration and distribution of neural progenitor cells transplanted into rats with focal cerebral ischemia, an MRI study, J. Cereb. Blood Flow Metab., 2010, 30, 653-662

[20] Pendharkar A.V., Chua J.Y., Andres R.H., Wang N., Gaeta X., Wang H., et al. Biodistribution of neural stem cells after intravascular therapy for hypoxic-ischemia, Stroke, 2010, 41, 2064-2070

[21] Longa E.Z., Weinstein P.R., Carlson S., Cummins R., Reversible middle cerebral artery occlusion without craniectomy in rats, Stroke, 1989, 20, 84-91

[22] Janowski M., Lyczek A., Engels C., Xu J., Lukomska B., Bulte J.W., et al., Cell size and velocity of injection are major determinants of the safety of intracarotid stem cell transplantation, J. Cereb. Blood Flow Metab., 2013, 33, 921-927

[23] Neumann-Haefelin T., Kastrup A., de Crespigny A., Yenari M.A., Ringer T., Sun G.H., et al., Serial MRI after transient focal cerebral ischemia in rats: dynamics of tissue injury, blood-brain barrier damage, and edema formation, Stroke, 2000, 31, 1965-1972

[24] Arbab A.S., Yocum G.T., Rad A.M., Khakoo A.Y., Fellowes V., Read E.J., et al., Labeling of cells with ferumoxides-protamine sulfate complexes does not inhibit function or differentiation capacity of hematopoietic or mesenchymal stem cells, NMR Biomed., 2005, 18, 553-559 
[25] Zietlow R., Lane E.L., Dunnett S.B., Rosser A.E., Human stem cells for CNS repair, Cell Tissue Res., 2008, 331, 301-322

[26] Goldman S.A., Stem and progenitor cell-based therapy of the central nervous system: hopes, hype, and wishful thinking, Cell Stem Cell, 2016, 18, 174-188

[27] Colter D.C., Class R., DiGirolamo C.M., Prockop D.J., Rapid expansion of recycling stem cells in cultures of plastic-adherent cells from human bone marrow, Proc. Natl. Acad. Sci. USA, 2000, 97, 3213-3218

[28] Honmou O., Houkin K., Matsunaga T., Niitsu Y., Ishiai S., Onodera R., et al., Intravenous administration of auto serum-expanded autologous mesenchymal stem cells in stroke, Brain, 2011, 134, 1790-1807

[29] Guzman R., De Los Angeles A., Cheshier S., Choi R., Hoang S., Liauw J., et al., Intracarotid injection of fluorescence activated cell-sorted CD49d-positive neural stem cells improves targeted cell delivery and behavior after stroke in a mouse stroke model, Stroke, 2008, 39, 13001306
[30] Ishizaka S., Horie N., Satoh K., Fukuda Y., Nishida N., Nagata I., Intra-arterial cell transplantation provides timing-dependent cell distribution and functional recovery after stroke, Stroke, 2013, 44, 720-726

[31] Chua J.Y., Pendharkar A.V., Wang N., Choi R., Andres R.H., Gaeta X., et al., Intra-arterial injection of neural stem cells using a microneedle technique does not cause microembolic strokes, J. Cereb. Blood Flow Metab., 2011, 31, 1263-1271

[32] Fukuda Y., Horie N., Satoh K., Yamaguchi S., Morofuji Y., Hiu T., et al., Intra-arterial transplantation of low-dose stem cells provides functional recovery without adverse effects after stroke, Cell Mol. Neurobiol., 2015, 35, 399-406

[33] Lee P.H., Lee J.E., Kim H.S., Song S.K., Lee H.S., Nam H.S., et al., A randomized trial of mesenchymal stem cells in multiple system atrophy, Ann. Neurol., 2012, 72, 32-40 